\title{
Assessment of risk awareness in medium-sized and large construction organizations in Kuwait
}

\author{
Amani Suliman Bu Qammaz* and Rufaidah Yousef AlMaian** \\ *Civil Engineering Department, Kuwait University, Kuwait \\ **Industrial and Management Systems Engineering Department, Kuwait University, Kuwait \\ Corresponding Author: amani.buqammaz@ku.edu.kw
}

$\begin{array}{ll}\text { Submitted: } & 05 / 04 / 2020 \\ \text { Revised: } & 07 / 06 / 2020 \\ \text { Accepted: } & 31 / 08 / 2020\end{array}$

\begin{abstract}
The construction business is extremely risky, and risks are faced in every project. Risk awareness has a significant influence on organizational strategy, and it can be argued that adequate risk awareness is critical for minimizing business risk. Despite the need for adequately understanding and managing business risk, it has been found that the level of risk awareness within the construction industry remains insufficient. In Kuwait, there is a lack of research studies that examine construction risk and risk management practices. This study represents an attempt to understand risk awareness within large- and medium-sized construction organizations in Kuwait. The study used an online survey that was sent to construction organizations registered under Category 1 in the Central Agency for Public Tenders (CAPT) in Kuwait. The findings of the survey revealed that owner-related factors, financial and economic risk, design risk and project complexity, subcontractor unavailability, labor unavailability, and political and government instability are the main concerns/risks faced. It is believed that the findings of this research could support efforts by construction organizations to eliminate such concerns and suggest other risks that may be overlooked by the studied organizations. The research findings indicated that $42 \%$ of the organizations rely on previous experience to manage risk and that only $25 \%$ of the organizations implement risk management processes, while $17 \%$ manage risk intuitively, and $16 \%$ by other approaches. Accordingly, it is critical to promote the systematic implementation of a risk management process in Kuwaiti construction organizations by revealing the advantages promised by such a process and providing a comprehensive understanding of risk attitude. Achieving this goal would aid the realization of the 2035 development vision of Kuwait, since most of the development projects within this vision involve international construction organizations, which may be advanced in the risk management field and thus be interested in understanding the level of risk awareness of their target market in Kuwait.
\end{abstract}

Keywords: Construction industry; Risk awareness; Construction risk; Risk management; Risk attitude.

\section{INTRODUCTION}

The construction industry is known for exhibiting unique characteristics. The uniqueness of the industry stems from the complex nature of construction projects, which represent the key products of this industry. The projects are diverse in type and scope, require the collaboration of parties with different business cultures, and cannot be performed in a controlled environment. In addition, each construction project is associated with a complicated decision-making process, in which decisions are made under a high level of uncertainty. Construction organizations must make assumptions related to their performance with respect to time, cost, quality, and safety, and such predefined assumptions are influenced by many uncertain factors. Examples of such factors include increases in materials costs, currency fluctuation, owner attitude, labor productivity, and weather conditions. Therefore, the consequences of the 
decisions made at the early stages of the project lifecycle may not be certain or controlled. The uncertain factors that may influence project objectives represent risk sources that must be identified and managed. Accordingly, the need to adequately understand the scope of a project and identify the associated risks is inevitable for achieving success. The systematic implementation of business risk identification, evaluation, and response is known as risk management (RM).

Compared to other industries, RM implementation in the construction industry remains immature, and there are many areas of implementation that require further investigation (Nnadi et al. 2018, Al-Azemi et al. 2014). One of the most important issues that is not adequately addressed is the level of awareness within construction organizations regarding systematic RM approaches. There are many research studies that have proposed efficient risk models (e.g., Al-Bahar and Crandall 1990, Tah and Carr 2001, Wang, Dulaimi, and Aguria 2004, Dikmen, Birgonul and Han 2007, Serpella, Ferrada, Howard and Rubio 2014) that were not adequately implemented by organizations, possibly because they lacked an awareness of and willingness to invest in RM.

RM in the construction industry in Kuwait is as in many other developing countries. That is, the relevant organizations may be aware of business risks, but they lack an appropriate management process with which to address these risks, which requires further research and analysis. The construction organizations in these countries have not reached maturity with respect to integrating formalized RM into their management process, and this failing is reflected in the poor performance of construction projects and a lack of consistency in responding to risk (Tah and Carr 2001, Serpella, Ferrada, Howard and Rubio 2014). With the absence of adequate and systematic RM, no proactive measures are available to control risks, and project risks are typically handled reactively. With its flexible decision-making process, the private sector may be able to benefit from RM strategies. However, public construction suffers from bureaucracy and lengthy decision-making, which makes it highly difficult to handle risks reactively without predetermined RM strategies (Bu-Qammaz 2015). Accordingly, it is crucial for any construction organization to possess an adequate level of risk awareness together with a systematic RM framework, which would help such organizations avoid negative risk consequences. It is believed that adopting a systematic approach for implementing a RM process in the construction industry maximizes the likelihood of achieving project success (Imbeah and Guikema, 2009).

\section{RM in the construction industry}

Construction involves many unforeseen risks, in addition to predictable risks (Smith 1992). Natural disasters are an example of unforeseen risks, while predictable risks may include design-related or financial risks. Risks occur in every project, and because certain risks are unpredictable, risk management requires a well-planned process for assessing and controlling the sources and consequences of project risks. According to Gunn (2005), risks and uncertainty are expected in all construction projects and may result in negative consequences for the three major project success criteria/indicators: time, quality, and budget. Similarly, Isik et al. (2010) considered that risk in any construction project is unavoidable and may significantly affect project performance, quality, and budget. However, RM practitioners have revealed that negative risk can be minimized by proper RM to reduce its undesirable effects (AlMaian 2014).

Construction projects are becoming increasingly complex, and as a result, the activities of construction organizations are becoming more diverse (Bu-Qammaz et al. 2009). Due to the unique characteristics of construction projects, risk management practitioners have recommended that systematic RM be implemented to ensure the achievement of project objectives (Hillson and Murray-Webster 2007). RM is an essential component of project management, and its importance is indicated the complex, dynamic, and difficult nature of construction projects (AlMaian et al. 2015). Bu-Qammaz et al. (2009) emphasized in their study on risk assessment that there is a consensus among all RM frameworks in the literature regarding the critical role of adequate identification and assessment of risks to achieve effective RM implementation.

Internationally, many construction organizations lack sufficient awareness of risk implementation in their projects. Introducing the RM process into construction organizations occurred relatively late compared to other industries. Baker et al. (1999) found that construction organizations had recently started to identify the importance of practicing formal RM. In addition, Bing and Tiong (1999) found that international construction risk models have considered 
country and government risks as one of the risk clusters that must be identified and assessed. Thus, it is believed that the developing countries are still behind in implementing a formal RM process into their construction industries. Nnadi et al. (2018) evaluated the level of RM awareness among construction stakeholders in Nigeria. They found that the level of RM awareness among construction stakeholders is low, particularly if compared with the relevant impact of risks on the industry.

To conclude, construction organizations must be aware of the associated risks if they are to adequately manage risk allocation and capitalize on their business opportunities. A recent study on the construction industry in China argues the importance of a reasonable allocation of risks among the client and the contractors to avoid unfair conduct by the client, such as shifting excessive risk to contractors, which results in higher premiums paid by the contractors to protect themselves from associated risks (Zhang et al. 2016).

\section{RM in the Construction Industry: The Case of Kuwait}

In Kuwait, one of the earliest studies on the assessment, allocation, and management of construction risks in the Kuwaiti construction industry was conducted by Kartam and Kartam (2001). Their study showed the significance of risk factors in causing project delays. Koushki et al. (2005) conducted a study on owner-experience problems, such as the risks of delay and cost overrun, during the construction of private residences in Kuwait. They found that there are no documented data in the literature on various risk-avoidance measures in the construction of private residences. In addition, Koushki et al. (2005) revealed that in the private residential project construction industry in Kuwait there is a lack of effective government regulations and control mechanisms regarding the qualifications of contracting organizations. Consequently, Koushki et al. (2005) found that the absence of government regulations has resulted in a large number of small contractors who are unqualified to execute private residential projects without incurring major risk problems. In a study on the RM framework for Build, Operate, and Transfer (BOT) projects in Kuwait, Al-Azemi et al. (2014) found that Kuwait has little experience in using private finance for its infrastructure projects, including a lack of experience in designing and implementing a RM framework for BOT projects. Al Zubaidi and Al Otaibi (2008) identified time overrun risk factors in Kuwaiti construction projects, and among the findings of their study is the nonavailability of organized information regarding risk factors and RM in the Kuwaiti construction industry.

An in-depth review of the literature on RM would reveal the absence of research studies related to RM in Kuwait. The authors of this study attempted to compile a list of available studies on RM practices in Kuwait and found that over the past two decades only a few such studies have been published. This finding emphasizes the need for conducting studies such as this one.

\section{RESEARCH METHOD}

The government of Kuwait is seeking partnerships with international business organizations to achieve its 2035 development vision (newkuwaitsummit.com/new-kuwait, site visited August 15 ${ }^{\text {th }}$, 2018). Construction expertise represents key know-how that is required to realize this vision. Most international organizations that are pursuing globalization are expected to be advanced in the area of risk awareness, and local construction organizations must possess a compatible understanding of construction risks in Kuwait. Therefore, there is an essential need to determine whether Kuwaiti construction organizations are advanced in their risk-assessment practices.

This research aims to assess the level of risk awareness and to develop an understanding of risk-related practices in medium and large construction organizations in Kuwait. The target is construction organizations registered under Category 1 in the Central Agency for Public Tenders (CAPT) in Kuwait. The research also aims to propose a general framework based on survey results that can be used to assess the level of risk awareness practices in construction organizations in Kuwait. The proposed framework can be considered as a general RM framework that can be effectively implemented by construction organizations to successfully utilize the RM process.

Accordingly, the objectives of the research can be summarized as follows: identify the risk awareness level in large and medium Kuwaiti construction organizations, reveal the main risks that may be faced in the Kuwaiti construction 
business environment, and provide an adequate framework that could help these organizations succeed in managing risks. The framework could promote systematic implementation of a RM process within construction organizations.

To achieve these objectives, the research followed the method depicted in Figure 1. The method can be summarized as follows:

1. Data collection: conduct a survey by using an online questionnaire to collect responses from construction organizations classified under CAPT Category 1 to reveal the current practices in Kuwaiti medium-sized and large organizations related to risk and to assess risk awareness for these organizations.

2. Data analysis: analyze the findings of the questionnaire and highlight the critical issues related to the awareness of business risks of the construction organizations.

3. Framework development: develop a conceptual framework based on the survey results for successful RM implementation in the construction organization in Kuwait to provide guidance for such organizations in improving their understanding of risk and its impact on their business strategies.

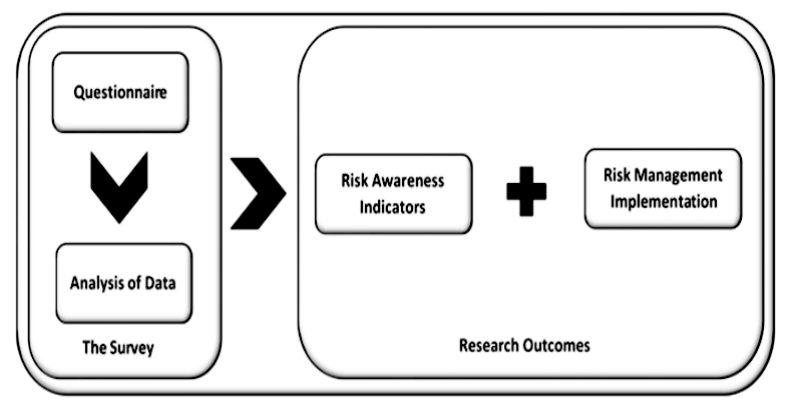

Figure 1. Research Method.

The questionnaire used for data collection consisted of 16 questions distributed into three sections. The first section included demographic questions that aimed to elicit general information regarding the construction organizations. The second part of the questionnaire was designed to reveal the bidding strategies implemented by the target organizations and the criteria that affect their bidding decisions. The last section of the questionnaire focused on RM. It was designed to examine the understanding of risk in the surveyed organizations and the tools they use to respond to risk.

The participants were first introduced to the aims of the research. The questionnaire started with a brief description of the research objectives and the anticipated significance of the survey results. It was also explained to the participants that the findings would be used to develop a risk management implementation framework that could help their organizations successfully manage construction risk.

\section{DATA COLLECTION}

An online survey approach was implemented. One reason for choosing this approach was to evaluate the level of acceptance regarding online tools as a communication medium by the target organizations.

The purpose of the survey was to collect information from construction organizations that would provide an understanding of the level of risk awareness of such organizations in Kuwait. The target organizations were Category 1 according to the CAPT, which divides the construction organizations in Kuwait into four main categories based on contract size and experience (https://capt.gov.kw/en/laws/, site visited July 14 ${ }^{\text {th }}$, 2018). CAPT Category 1 represents the highest rank that an organization can attain under agency categorization criteria. According to article 19 of the implementing regulations of law number 49 of 2016 for public tenders, to qualify for registration under Category 1, the capital owned by an organization should not be less than ten million Kuwaiti dinars (https://capt.gov.kw/en/laws/, site visited July $14^{\text {th }}, 2018$ ). 
The total number of construction organizations registered under civil and construction works was 82 (https://capt. gov.kw/en/, site visited July $14^{\text {th }}, 2018$ ). However, a certain of these organizations were idle, or their activities were suspended, while others were excluded from the surveyed organizations, because their activities were irrelevant. Accordingly, 25 organizations were excluded. Subsequently, 57 construction organizations that were considered potential candidates were emailed the link to the survey. The survey and the recruiting email were sent to the organizations. The email explained who should provide the responses. Two weeks later, a follow-up email was sent with a reminder message. A week after the follow-up email was sent, a final reminder was sent.

According to the collected results, 28 of the 57 targeted organizations followed the provided emailed link to open the survey, i.e., $49 \%$ of the emailed organizations. However, the total number of organizations that registered responses was 15 , whereby 2 organizations did not answer most of the questions. If only the 28 organizations who opened the survey are considered, the response rate was $54 \%$, which is a relatively high participation rate considering the nature of the questionnaire. Accordingly, the results were considered acceptable, and the analysis commenced. The data collected from the questionnaire are analyzed and discussed in the following section.

\section{DATA ANALYSIS}

The questionnaire was structured to collect data regarding the target organizations' risk-related practices that would help during the analysis to evaluate the level of awareness of the construction organizations to construction risk associated with the business environment in Kuwait.

The first question requested the participants to indicate the size of their organization. The selection criterion was the company's assets in Kuwaiti dinars (KWD), and the organizations were categorized as follows: medium-sized if the company's assets were between 5 million and 10 million KWD or large if the company's assets were more than 10 million KWD. The responses to this question revealed that $77 \%$ of the organizations were large and only $23 \%$ were medium-sized, and since all the organizations were from CAPT Category 1, their assets must have been 10 million KWD or more. It is worth mentioning that of the 15 organizations that provided responses only 13 revealed their sizes. This result is important since organization size reflects the size and complexity of the projects an organization would be involved in, whereby, logically, larger organizations would be involved in larger and more complex projects. It can be argued that larger and more complex projects involve more risk.

Next, the questionnaire aimed to examine the area of interest regarding construction project type. The respondents were requested to select all types that applied. The responses are provided in Table 1. The results indicate that the activities of the responding organizations are diverse and include all the proposed types. In addition, 2 organizations defined other project types, including oil- and gas-related construction projects. Having responses from organizations that are involved in diverse construction activities is essential for the reliability and comprehensiveness of the survey's results since it reflects the level of risk awareness from organizations with different perspectives.

Table 1. Organizations' activities with respect to construction project types.

\begin{tabular}{|l|c|c|}
\hline Construction Project Type & Number of Organizations & $\mathbf{\%}$ \\
\hline Public & 10 & 23.81 \\
\hline Commercial & 8 & 19.05 \\
\hline Industrial & 8 & 19.05 \\
\hline Residential & 8 & 19.05 \\
\hline Infrastructure & 6 & 14.29 \\
\hline Other & 2 & 4.76 \\
\hline
\end{tabular}


To elicit the size of the projects that the respondents were involved in for each project type, the respondents were asked to indicate the corresponding size for each project. Here, the project size was defined with respect to its budgeted cost: small project, $<5$ million KWD; medium-sized project, 5 million to 25 million KWD; and large project, $>25$ million KWD. It was found that most of the organizations preferred medium-sized public projects $(12.5 \%$ of the respondents), whereas the remaining organizations preferred large industrial projects (the same percentage). Table 2 provides an analysis of the project sizes and types as preferred by the responding organizations. The results reveal that none of the participating organizations were interested in medium-sized commercial or small commercial or infrastructure projects.

Table 2. Organizations' activities with respect to project size and type.

\begin{tabular}{|c|c|c|c|}
\hline \multicolumn{2}{|l|}{ Project Type } & $\begin{array}{c}\text { Number of } \\
\text { Organizations }\end{array}$ & $\%$ \\
\hline \multirow{4}{*}{ Small } & Industrial & 2 & 8.33 \\
\hline & Public & 2 & 8.33 \\
\hline & Residential & 1 & 4.17 \\
\hline & Other & 1 & 4.17 \\
\hline \multirow{5}{*}{ Medium-sized } & Public & 3 & 12.5 \\
\hline & Residential & 2 & 8.33 \\
\hline & Industrial & 1 & 4.17 \\
\hline & Infrastructure & 1 & 4.17 \\
\hline & Other & 1 & 4.17 \\
\hline \multirow{6}{*}{ Large } & Industrial & 3 & 12.5 \\
\hline & Commercial & 2 & 8.33 \\
\hline & Public & 2 & 8.33 \\
\hline & Infrastructure & 1 & 4.17 \\
\hline & Residential & 1 & 4.17 \\
\hline & Other & 1 & 4.17 \\
\hline
\end{tabular}

The next two questions (i.e., Questions 4 and 5) of the questionnaire focused on measuring the effect of contract type (e.g., lump-sum, unit price, and cost plus fee) and project delivery system (e.g., design-bid-build, design-build) on the bidding decisions of the organizations. The results revealed that nearly all of the responding organizations perceived that these factors had a noteworthy influence on the level of project risk. With respect to delivery system, 8 organizations agreed that it had an influence on their bid/no bid decisions, while only one organization responded that it does not consider the delivery system a factor that affects the bidding decision. Reviewing the overall responses of this specific organization revealed that it is a large organization interested in large public industrial and infrastructure projects. In these types of project, the government typically implements similar contract types and project delivery systems, which explains why contract type and project delivery system are not considered by the organization when bidding for such projects. In addition, this organization's activities are focused on these two types of project, and thus, the level of risk may be well comprehended by the organization. More specifically, the organization's responses revealed that it relies on its previous experience and its own risk assessment in making its strategic decisions. The responses received regarding the contract types and project delivery systems are summarized in Table 3. 
Table 3. Consideration of the contract type and project delivery system in bid/no bid decisions.

\begin{tabular}{|c|c|c|c|c|c|c|}
\hline \multirow{3}{*}{ Contract Type } & \multicolumn{2}{|c|}{ Yes } & \multicolumn{2}{|c|}{ No } & \multicolumn{2}{|c|}{ Sometimes } \\
\hline & $\begin{array}{c}\text { No. of } \\
\text { Organizations }\end{array}$ & $\%$ & $\begin{array}{c}\text { Number of } \\
\text { Organizations }\end{array}$ & $\%$ & $\begin{array}{c}\text { Number of } \\
\text { Organizations }\end{array}$ & $\%$ \\
\hline & 9 & $69.23 \%$ & 3 & $23.08 \%$ & 1 & $7.69 \%$ \\
\hline \multirow{3}{*}{$\begin{array}{l}\text { Project Delivery } \\
\text { System }\end{array}$} & \multicolumn{2}{|c|}{ Yes } & \multicolumn{2}{|c|}{ No } & \multicolumn{2}{|c|}{ Sometimes } \\
\hline & $\begin{array}{c}\text { No. of } \\
\text { Organizations }\end{array}$ & $\%$ & $\begin{array}{c}\text { No. of } \\
\text { Organizations }\end{array}$ & $\%$ & $\begin{array}{c}\text { No. of } \\
\text { Organizations }\end{array}$ & $\%$ \\
\hline & 8 & $88.89 \%$ & 1 & $11.11 \%$ & 0 & 0 \\
\hline
\end{tabular}

Next, the questionnaire aimed to reveal the approaches that are followed by the organizations in defining bid markups for a given bid proposal. These approaches provide important insight regarding the organizations' risk awareness. The questionnaire sought to establish the following: experience, fixed percentage, variable percentage, and risk assessment. Additionally, the respondents were permitted to list other approaches if the provided list did not include their preferred ones. The responses (Table 4) indicate that most of the organizations rely on previous experience in defining bid markups. However, it was also found that 5 organizations assessed risk. It must be emphasized that the response to this question was not restricted to one answer. That is, the respondent could choose more than one option. It is also worth mentioning that all the organizations that indicated they undertook risk assessment also selected experience. In other words, $50 \%$ of the organizations responded that experience was an implemented approach in defining bid markup.

Table 4. Approaches implemented to define bid markup.

\begin{tabular}{|l|c|c|}
\hline Approaches & Number of Organizations & $\mathbf{\%}$ \\
\hline Experience & 10 & 43.48 \\
\hline Risk Assessment & 5 & 21.74 \\
\hline Fixed \% & 4 & 17.39 \\
\hline Variable \% & 4 & 17.39 \\
\hline
\end{tabular}

In the next question, the participants were asked to define the main criteria that their organizations considered when assigning bid markup value. Here, the monetary value of the bid markup added to the bid proposal was the focus of the question. The results revealed that competitiveness was the most important criterion followed by the organization's need for the project, while project stakeholders and project risk were less important (Table 5). It was noted that the 5 organizations that selected project risk were organizations that also selected risk assessment as an approach to defining bid markup. Again, the respondents were permitted to indicate all applicable criteria or define other criteria.

Table 5. Main criteria considered in defining bid markup value.

\begin{tabular}{|l|c|c|}
\hline Criteria & Number of Organizations & \% \\
\hline Competitiveness & 9 & 36.00 \\
\hline Need for the Project & 8 & 32.00 \\
\hline Project Risk & 5 & 20.00 \\
\hline Project Stakeholders & 3 & 12.00 \\
\hline
\end{tabular}


The questionnaire then attempted to determine whether the organizations' preferable market was local or global. The target market has an important influence on the organizations' willingness to identify and manage risk. It was anticipated that if an organization seeks to do business globally it would have more risk awareness since international construction projects are known to be riskier than local construction. The results shown in Figure 2 indicate that 54\% of the organizations had no interest in conducting business globally.

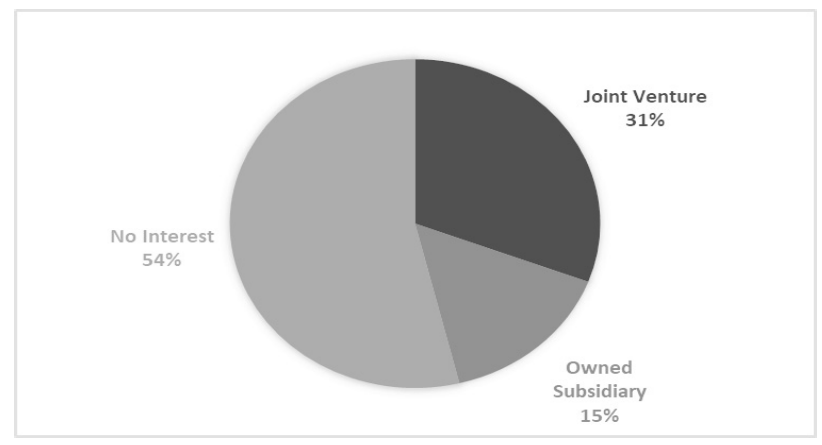

Figure 2. Organizations' Preferred Strategy to Conduct Business Globally.

The factors that affect an organization's strategic decision to enter a foreign country were the subject of the following question. As shown in Figure 3, the results reveal in that the project and country risk were the most important factors, which indicates that organizations that are willing to expand their business are aware of the importance of considering the associated risks.

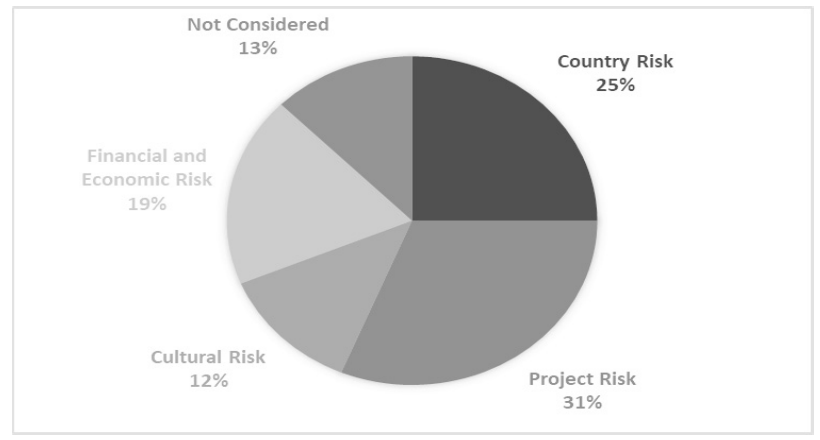

Figure 3. Factors considered by the organizations regarding entering a foreign country.

The respondents were then asked to focus on the risk factors related to their business. An open-ended question enabled the participants to list the most critical threats/risks that were/would be faced by their organizations while conducting business. In line with the previous questions, only 5 organizations defined their risks. As shown in Table 6 , the results indicate that the most critical risk was owner-related risk, followed by financial and economic risk and design risk as equally important, and then the unavailability of qualified subcontractors. It can be observed that there is a consensus between the organizations' defined risks and the results of other research studies that investigated construction risk in Kuwait, such as Koushki et al. (2005), Al Zubaidi and Al Otaibi (2008), and BuQammaz (2015). 
Table 6. Most critical risk factors.

\begin{tabular}{|l|c|c|}
\hline Risk Factor & Number of Organizations & \% \\
\hline Owner-Related Factors & 4 & 28.57 \\
\hline Design Risk and Project Complexity & 3 & 21.43 \\
\hline Financial and Economic Factors & 3 & 21.43 \\
\hline Subcontractor Unavailability & 2 & 14.29 \\
\hline Political and Government Instability & 1 & 7.14 \\
\hline Labor Unavailability & 1 & 7.14 \\
\hline
\end{tabular}

Figure 4 lists the means by which the organizations respond to their business risks. The chart presented in the figure can help construction organizations assess their risk awareness and how they respond to risk. The results indicate that most of the surveyed organizations respond to risk based on previous experience rather than by implementing systematic RM. However, one large organization with diverse activities that considered risk assessment as a strategic decision tool revealed that lean strategies are used to respond to their business risk.

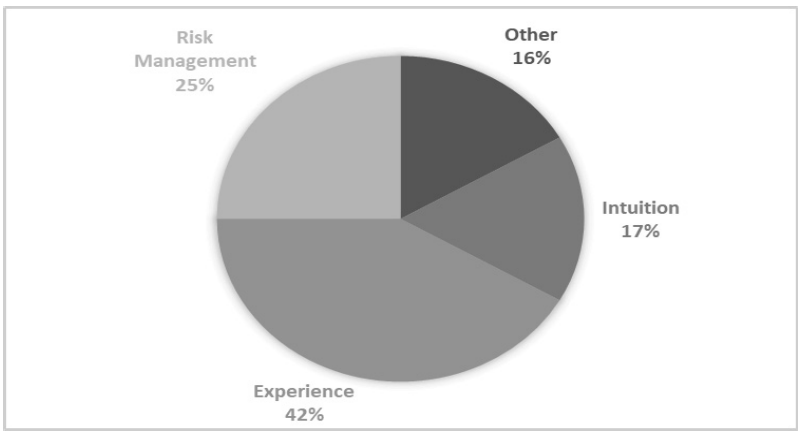

Figure 4. Organizations' approaches to managing business risk.

Another important indicator of risk awareness is the readiness of an organization to dedicate an independent team to manage business risk. The results indicate that only 4 organizations have such independent risk management teams. Subsequently, the organizations were asked a hypothetical question: "If your organization considers RM as an independent discipline, which of the following best describes your organization RM discipline?" The responses appear in Figure 5.

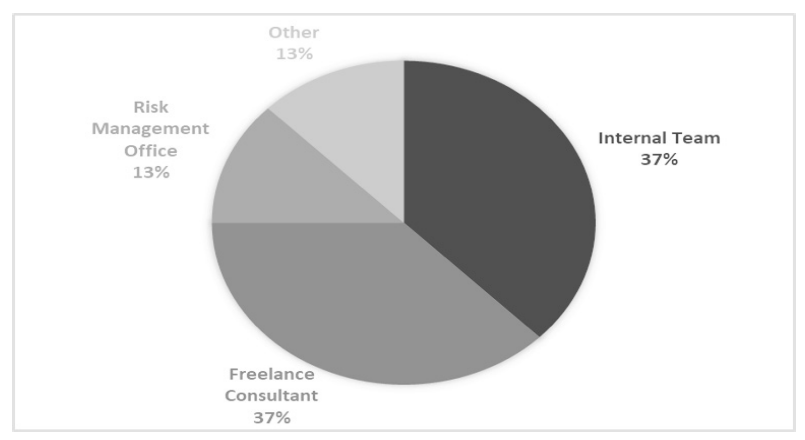

Figure 5. How the organizations consider their RM discipline. 
To assess the importance of the recommendations provided by the RM experts if the organization considers RM while making strategic decisions, the respondents were asked whether these recommendations would be considered before making any decision. All 4 organizations that have an independent RM team responded that they consider the team's recommendations, which means that the organizations that implement a RM process within their strategic decision-making are aware of its significance.

However, it is essential to understand the response strategies that are used to manage risk by these organizations. Thus, the respondents were asked to choose from four main response strategies: joint venture, insurance, subcontracting, and contingency. Table 7 presents the results for this question. Joint ventures and subcontracting are risk-sharing strategies, while insurance represents a monetary compensation strategy. However, insurance cannot recover the time lost in delays, cover the time overrun consequences of risk, or compensate for the reputational risks that would be encountered in case of risk occurrence.

Table 7. Risk Response Strategies of the Organizations.

\begin{tabular}{|l|c|c|}
\hline Strategy & Number of Organizations & $\mathbf{\%}$ \\
\hline Insurance & 4 & 44.44 \\
\hline Joint venture & 2 & 22.22 \\
\hline Contingency & 2 & 22.22 \\
\hline Subcontracting & 1 & 11.11 \\
\hline
\end{tabular}

Finally, the questionnaire was concluded by addressing the main competitive strategies adopted by the organizations. The competitive advantages perceived by the organizations reveal their understanding of the risks associated with the construction business environment. Table 8 lists the results. As shown in the table, most of the organizations selected reputation as their competitive advantage in the market, followed by lowest price, which is understandable if it is understood that the lowest price is the main criterion for success in public bids. Quality of product, differentiation, and diversification all had the same response percentages.

Table 8. Competitive strategies of the organizations.

\begin{tabular}{|l|c|c|}
\hline Strategy & Number of Organizations & \% \\
\hline Reputation & 6 & 31.58 \\
\hline Lowest Price & 4 & 21.05 \\
\hline Differentiation & 3 & 15.79 \\
\hline Diversification & 3 & 15.79 \\
\hline Quality & 3 & 15.79 \\
\hline
\end{tabular}

Reviewing the findings of the survey, one can state that the construction organizations are aware of most of the risks associated with their business but still lack an awareness of the importance of systematically managing such risks. The results reveal that most of the organizations rely on previous experience to respond to risk and do not invest systematically in managing risk. To validate the survey findings and to ensure the reliability of the collected responses, which represent a preliminary understanding of the current situation regarding construction risk in Kuwait, five construction experts in Kuwait were contacted to discuss their views on construction organization risk awareness and the systematic implementation of the RM framework in Kuwait. Each expert had more than 20 years of experience in the construction business, and the experts represented both the public and private sectors. The discussion resulted in a consensus among the experts, who all confirmed Kuwait's construction organizations lacked the requisite awareness 
regarding the RM process. They also indicated that both the private and public sectors in Kuwait are lacking essential knowledge on how to identify and effectively respond to business risk. In addition, it was agreed that this fact is one of many reasons for the frequent failure of construction projects in Kuwait, primarily public projects. According to the experts, systematic implementation of RM in construction organizations is inevitable if such organizations are to comply with the more stringent and complex requirements of the new era in Kuwait in connection with its 2035 development vision. The conceptual framework proposed in this research represents an approach to facilitating this implementation, and the experts agreed that the country's construction organizations must consider their strategic objectives together with project specific objectives to create an RM model that would help them realize business success.

\section{FRAMEWORK DEVELOPMENT}

In addition to a desire to understand the risk awareness of the surveyed construction organizations, the main motivation of this research is to promote systematic RM implementation among such organizations. The collected responses revealed that much remains to be achieved to reach a mature level in the use of systematic RM in the construction industry in Kuwait. Therefore, the framework proposed in this research is focused on how to create a supportive environment to develop and adopt an adequate RM framework that could be used effectively by an organization. The framework is presented in Figure 6.

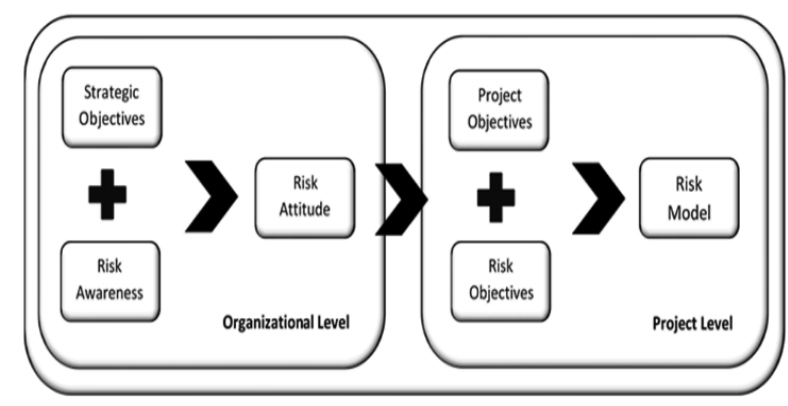

Figure 6. Risk Management Implementation Framework.

The framework considers two different levels: the organizational and project levels. In addition, under each level, several attributes are defined. The organizational level concerns organizational strategic objectives, risk awareness, and risk attitude, while the project level focuses on project-specific objectives, risk model objectives, and developing the risk model. The proposed framework is defined based on the premise that to achieve the promised advantages of RM organizations must first comprehend their objectives and the associated risks. Then, each project objective will guide the definition of the risk model objectives. Finally, the risk model can be developed considering both the organizational attitude towards risk and the project-specific risks. According to Hillson and Murray-Webster (2007), risk attitude can be defined as "a chosen response to an uncertainty that matters, influenced by perception". Organizations respond to risk in diverse manners, and for an organization to form an attitude towards risk, the organization's strategic objectives and business risk must be understood first. The risk model should consider the specific project and risk objectives since with different objectives different risk models are initiated. Finally, risk models can be developed to address either organizational risks or project specific risks. The objectives must be defined first. Then, consistency must be assured to achieve effective RM.

The developed risk implementation framework could aid construction organizations that lack sufficient risk awareness to develop their own business risk model using both their strategic and project-specific objectives. By following the concepts provided in the framework, it is believed that such an organization can create a reliable risk model. First, the organization must define its strategic objectives related to its business needs and priorities. Then, the organization must examine the associated risks and opportunities of its business environment, which reflects its risk 
awareness. Considering its strategic objectives together with its risk and opportunities, the organization can define the different acceptable responses towards the identified risks. This organization's adopted mindset is its "risk attitude". At the project level, the organization must use the predefined responses to react to the anticipated risk. The defined project-specific objectives guide the definition of the risk objectives at the project level, and these objectives should be used to define the project risk model.

\section{CONCLUSION}

The described research focused on construction organizations that are registered under Category 1 in the CAPT, the agency that is responsible for public tenders in Kuwait. The results indicate that risk awareness continues to be lacking in construction organizations, particularly with respect to managing business risks. The surveyed organizations' responses reveal that most of the organizations use previous experience to manage risk. The organizations rely on experience to define their bid markups while considering market competitiveness and their need for a project in determining its value. This finding indicates a lack of systematic approaches in considering business risk while defining bid markup because the implemented methods are intuitive in nature.

The results also reveal that the organizations are aware of the risks associated with their business and consider owner-related risk, financial and economic risk, design risk, and the unavailability of qualified subcontractors as the most critical risks facing the construction business in Kuwait. In addition, the response strategies implemented by the organizations to mitigate risk are all risk transfer and sharing strategies. No risk mitigation strategy that could be described as a proactive response to mitigate anticipated risks was identified in any of the surveyed organizations. In contrast, the research also revealed that the online approach to collecting data is still not accepted by most organizations compared to other communication tools.

In closing, it is worth mentioning that only 5 organizations had established their own RM practices, but it was also concluded that their RM implementation was not yet mature. The survey results clearly reveal that much remains to be achieved in this area and that additional efforts are needed to promote systematic and effective RM implementation in the Kuwaiti construction environment. The maturity of the construction market in implementing systematic RM approaches is critical not only for the survival of local organizations in the market but also for the success of international organizations interested in playing a role in achieving the predetermined development plans of Kuwait.

\section{ACKNOWLEDGMENT}

This research is part of project No. EV01/17, entitled "An assessment of risk awareness of medium and large size construction organizations in Kuwait", funded by the Office of the Vice President for Research - Kuwait University.

\section{REFERENCES}

Al-Azemi, K.F., Bhamra, R., and Salman, A.F.M. 2014. Risk management framework for build, operate and transfer (bot) projects in kuwait. Journal of Civil Engineering and Management, 20(3): 415-433. doi:10.3846/13923730.2013.802706.

Al-Bahar J.F. and Crandall K.C. 1990. Systematic Risk Management Approach for Construction Projects. Journal of Construction Engineering and Management, 116(3): (533).

Al Zubaidi, H., and Al Otaibi, S. 2008. An empirical approach for identifying critical time-ovrerun risk factors in Kuwait's construction projects. Journal of Economic and Administrative Sciences, 24(2): 35-53. doi:10.1108/10264116200800007.

AlMaian, R.Y. 2014. A strategic approach to effectively manage supplier quality within the construction industry. Theses and Dissertations, University of Arkansas, Fayetteville.

AlMaian, R.Y., Needy, K.L., Walsh, K.D., and Alves, T.D.C.L. 2015. Supplier quality management inside and outside the construction industry. Engineering Management Journal, 27(1): 11-22. doi:10.1080/10429247.2015.11432032.

Baker, S., Ponniah, D., and Smith, S. 1999. Survey of risk management in Major U.K. companies. Journal of Professional Issues in Engineering Education and Practice, 125(3): 94-102. doi:10.1061/(asce)1052-3928(1999)125:3(94). 
Bing, L., \& Tiong, R.L.K. 1999. Risk Management Model for International Construction Joint Ventures. ASCE Journal of Construction Engineering and Management, 125: 377-384.

Bu-Qammaz, A.S., Dikmen, I., and Birgonul, M.T. 2009. Risk assessment of international construction projects using the analytic network process. Canadian Journal of Civil Engineering, 36(7): 1170-1181. doi:10.1139/109-061.

Bu-Qammaz, A.S. 2015. Risk management model for international construction joint venture projects in Kuwait. OhioLINK Electronic Theses and Dissertations Center, Ohio State University. Department of Civil, Environmental, and Geodetic Engineering: 346.

Dikmen I, Birgonul M.T., and Han S. 2007. Using fuzzy risk assessment to rate cost overrun risk in international construction projects. International Journal of Project Management, 25(5): 494-505.

Gunn, S. 2005. Consideration of pre-contract risks in International PFI projects. Risk management considerations in construction projects. The University of Salford, Manchester, Salford Centre for Research and Innovation (SCRI), Cheshire, UK.

Hillson, D., and Murray-Webster, R. 2007. Understanding and managing risk attitude. Gower Publishing, Farnham, UK.

Imbeah, W. \& Guikema, S. 2009. Managing construction projects using the advanced programmatic risk analysis and management model. Journal of Construction Engineering and Management, 135: 772-781.

Isik, Z., Arditi, D., Dikmen, I., and Birgonul, M.T. 2010. Impact of resources and strategies on construction company performance. Journal of Management in Engineering, 26(1): 9-18. doi:10.1061/(asce)0742-597x(2010)26:1(9).

Kartam, N.A., and Kartam, S.A. 2001. Risk and its management in the Kuwaiti construction industry: a contractors' perspective. International Journal of Project Management, 19(6): 325-335. doi:10.1016/s0263-7863(00)00014-4.

Koushki, P.A., Al-Rashid, K., and Kartam, N. 2005. Delays and cost increases in the construction of private residential projects in Kuwait. Construction Management and Economics, 23(3): 285-294. doi:10.1080/0144619042000326710.

Nnadi, E.O.E., Enebe, E.C., and Ugwu, O.O. 2018. Evaluating the awareness level of risk management amongst construction stakeholders in Nigeria. International Journal of Construction Engineering and Management, 7(1): 47-52. doi: 10.5923/j. ijcem.20180701.05.

Smith, R.J. 1992. Risk management for underground projects: Cost-saving techniques and practices for owners. Tunnelling and Underground Space Technology, 7(2): 109-117. doi:10.1016/0886-7798(92)90040-O.

Serpella, A.F., Ferrada, X., Howard, R., \& Rubio, L. 2014. Risk management in construction projects: a knowledge-based approach. Procedia - Social and Behavioral Sciences, 119: 653-662.

Tah J.H.M. and Carr V. 2001. Knowledge-Based Approach to Construction Project Risk Management. Journal of Comuting in Civil Engineering (2001). 15(3): 170-177.

Wang, S.Q., Dulaimi, M.F. and Aguria, M.Y. 2004. Risk Management Framework for Construction Projects in Developing Countries. Construction Management and Economics, 22: 237-252. http://dx.doi.org/10.1080/0144619032000124689.

Zhang, S., Zhang, S., Gao, Y. \& Ding, X. 2016. Contractual governance: effects of risk allocation on contractors' cooperative behavior in construction projects. Journal of Construction Engineering and Management, 142: 04016005. 